\title{
Minh bạch và trách nhiệm giải trình trong thực hiện chính sách lâm nghiệp tại Việt Nam
}

\author{
Phạm Thu Thủy và Ngô Hà Châu
}

\section{Thông điệp chính}

- Cộng đồng quốc tế cũng như Chính phủ Việt Nam đã cam kết nâng cao tính minh bạch và trách nhiệm giải trình trong việc thực thi chính sách công nói chung và các chính sách của ngành lâm nghiệp nói riêng thông qua nhiều chính sách hiện hành, ví dụ như Luật tiếp cận thông tin, Luật Phòng chống tham nhũng, và hệ thống cấp quốc gia cung cấp thông tin về việc xem xét và tuân thủ các nguyên tắc đảm bảo an toàn Cancun trong quá trình thực thi REDD+.

- Tuy nhiên, thực hiện nâng cao tính minh bạch và trách nhiệm giải trình trong thực hiện chính sách lâm nghiệp tại Việt Nam gặp nhiều khó khăn bởi việc thiếu sự sẵn có, độ tin cậy và sự chính xác về số liệu; sự tham gia của người dân vào quá trình ra chính sách còn gặp nhiều khó khăn; chia sẻ thông tin giữa các bên, thực thi pháp luật về minh bạch và trách nhiệm giải trình còn hạn chế.

- Việc thực thi, theo dõi, giám sát và đánh giá các chính sách liên quan đến minh bạch và trách nhiệm giải trình đòi hỏi định nghĩa, phương pháp đánh giá rõ ràng, nâng cao năng lực cho các bên có liên quan trong lĩnh vực chia sẻ thông tin, đồng thời cải thiện hành lang pháp lí liên quan đến thực thi chính sách kịp thời và đầy đủ.

\section{Giới thiệu}

Quản trị lâm nghiệp với sự tham gia tích cực của các bên có liên quan cùng với tính minh bạch và trách nhiệm giải trình được coi là những yếu tố quan trọng quyết định sự thành công và hiệu quả các các chính sách lâm nghiệp trên toàn cầu. Khung Hiệp ước về Biến đổi Khí hậu của Liên Hợp Quốc (UNFCCC) cũng yêu cầu các quốc gia trên thế giới xây dựng một hệ thống báo cáo và giám sát đáng tin cậy, minh bạch và đầy đủ về nguồn phát thải, các hoạt động và chính sách đóng góp vào giảm phát thải trên toàn cầu. $C u$ thể hơn, Điều 13 của Thỏa thuận Paris cũng thiết lập Khung tăng cường minh bạch hóa trong chính sách và sáng kiến giảm phát thải và ứng phó và thích ứng với biến đổi khí hậu. Các sáng kiến quốc tế trong ngành lâm nghiệp, bao gồm Giảm phát thải từ phá rừng và suy thoái rừng (REDD+) và Hiệp định Tăng cường luật pháp, Quản lý và Thương mại lâm sản (FLEGT) / Hiệp định đối tác tự nguyện (VPA), cũng đề cập tới tính minh bạch và trách nhiệm giải trình như là những trụ cột quan trọng, cốt lõi trong việc thực hiện các sáng kiến này. Mặc dù minh bạch và trách nhiệm giải trình thường xuyên được đề cập đến trên diễn đàn, chương trình nghị sự biến đổi khí hậu quốc tế cũng như các chương trình dự án, cho tới nay chưa hề có một định nghĩa chung về hai khái niệm này. Các chính phủ, tổ chức và các bên có cách nhìn nhận rất khác nhau về nội hàm thế nào là minh bạch và thế nào là trách nhiệm giải trình. Người dân ở các nước khác nhau cũng có nhìn nhận về tính minh bạch khác nhau (Piotrowski và Van Ryzin 2007) tùy vào từng bối cảnh chính trị cụ thể (Cucciniello và cộng sự 2017). Các phương pháp đánh giá minh bạch và tính giải trình khác nhau cũng dẫn đến kết quả khác nhau.

Các bên có liên quan đôi khi thậm chí còn nhầm lẫn hai khái niệm này là một và không tách bóc được rõ ràng sự khác biệt. Chính điều này dẫn đến việc các chính sách và hoạt động cụ thể hóa Khung tăng 
cường tính minh bạch trong Thỏa thuận Paris và nhiều chính sách lâm nghiệp khác gặp khó khăn và không hiệu quả. Báo cáo này rà soát lại các tài liệu, chính sách, báo cáo trong và ngoài nước nhằm cung cấp thông tin về định nghĩa, phương pháp tiếp cận và đánh giá tính minh bạch và trách nhiệm giải trình trong chính sách công nói chung và chính sách lâm nghiệp nói riêng.

\section{Định nghĩa và cách tiếp cận trong việc đánh giá tính minh bạch}

Cho tới nay có nhiều định nghĩa về tính minh bạch đã được đưa ra. Theo Cucciniello và cộng sự (2017), minh bạch là một thuật ngữ rộng có thể được sử dụng để mô tả mức độ công bố và phổ biến của thông tin liên quan đến bất kỳ công việc nào của chính phủ. Tính minh bạch cũng có thể được hiểu là một tiêu chuẩn về lượng thông tin mà một chương trình, chính sách hoặc dự án cần phải cung cấp công khai, liên quan đến mọi quá trình và quy trình thực hiện và tham vấn các bên có liên quan (Estrada 2011). Minh bạch cũng được coi như như một giá trị công được xã hội chấp nhận để phòng chống tham nhũng đi kèm với trách nhiệm giải trình (Ball 2009).

Khái niệm minh bạch còn có nhiều khía cạnh:

1. Minh bạch về chính trị bao gồm các thông tin và minh chứng cho việc các chính phủ đã thực hiện chế độ dân chủ và hiến pháp ra sao, cũng như năng lực phổ cập giáo dục của xã hội như thế nào (Meijer và cộng sự 2018). Tính minh bạch về chính trị cũng đề cập tới thông tin về các quan chức được bầu, từ mức lương đến sự tham gia của họ vào các quá trình ra quyết định khác nhau (Cucciniello và Nasi 2014).

2. Minh bạch hành chính bao gồm các thông tin liên quan đến quá trình, trình tự, thủ tục mà các tổ chức hành chính công thực thi các chính sách và hoạt động kinh tế có hiệu quả, cũng như các chức năng mà các tổ chức hành chính công được giao phó và kết quả thực thi (Meijer và cộng sự 2018; Cucciniello và cộng sự 2017).

3. Minh bạch ngân sách bao gồm các hoạt động kinh tế có hiệu quả, có liêm chính hay không và khả năng bền vững cũng như phục hồi khi có rủi ro và suy thoái về kinh tế như thế nào (Meijer và cộng sự 2018).
Cho tới nay, nhiều chương trình, dự án, nghiên cứu trên toàn cầu và tại Việt Nam chủ yếu tập trung vào minh bạch chính trị và minh bạch tài chính, trong khi minh bạch hành chính thường nhận được rất ít quan tâm (Cucciniello và cộng sự 2017). Tuy nhiên, để khẳng định một chính phủ vững mạnh, một chương trình hay một dự án minh bạch thì cần nhìn nhận cả 3 lĩnh vực liên quan đến tính minh bạch trên đây.

Có nhiều tiêu chí để đánh giá tính minh bạch của một chính sách, chương trình và dự án; tuy nhiên, các học giả, chương trình dự án và chính sách của các nước yêu cầu cần phải nhìn nhận minh bạch trên 3 yếu tố sau:

1. Cách thức, quyền và khả năng tiếp cận thông tin (Cucciniello và cộng sự 2017; Schnell 2018). Fox (2007) cho rằng khi đánh giá tiếp cận thông tin cần được xem xét trên 2 khía cạnh:

a. Tính chủ động của chính phủ và tổ chức trong việc công khai các thông tin của mình nhằm xây dựng và củng cố niềm tin của công dân đối với chính phủ

b. Theo nhu cầu: cam kết thể chế mà chính phủ và các bên liên quan về việc đáp ứng yêu câu của công dân về tiếp cận các loại thông tin và tài liệu

2. Sự tương tác và giao tiếp chia sẻ thông tin hai chiều (Cucciniello và cộng sự 2017; Schnell 2018). Theo Heald (2012) và Cucciniello cùng cộng sự (2017) thông tin hai chiều phải có đủ cả 4 khía cạnh dưới đây, dù trong thực tế phần lớn các chính sách và dự án chỉ quan tâm đến một trong 4 loại hình:

a. minh bạch nội bộ: khi những người bên ngoài có thể quan sát những gì đang diễn ra bên trong tổ chức,

b. minh bạch hướng ngoại: khi những người bên trong một tổ chức có thể quan sát những gì đang xảy ra bên ngoài tổ chức,

c. minh bạch từ cấp dưới lên trên: khi những người cấp dưới có quyền được tiếp cận thông tin về các quyết định của cấp trên. Quyền được biết và Quyền tiếp cận thông tin nằm trong khái niệm minh bạch này.

d. minh bạch từ cấp trên xuống cấp dưới: khi những người cấp trên có quyền được truy cập thông tin và kiểm tra cấp dưới

3. Tính rõ ràng về quy trình thủ tục ra quyết định (Schnell 2018). Fox (2007) cho rằng minh bạch rõ 


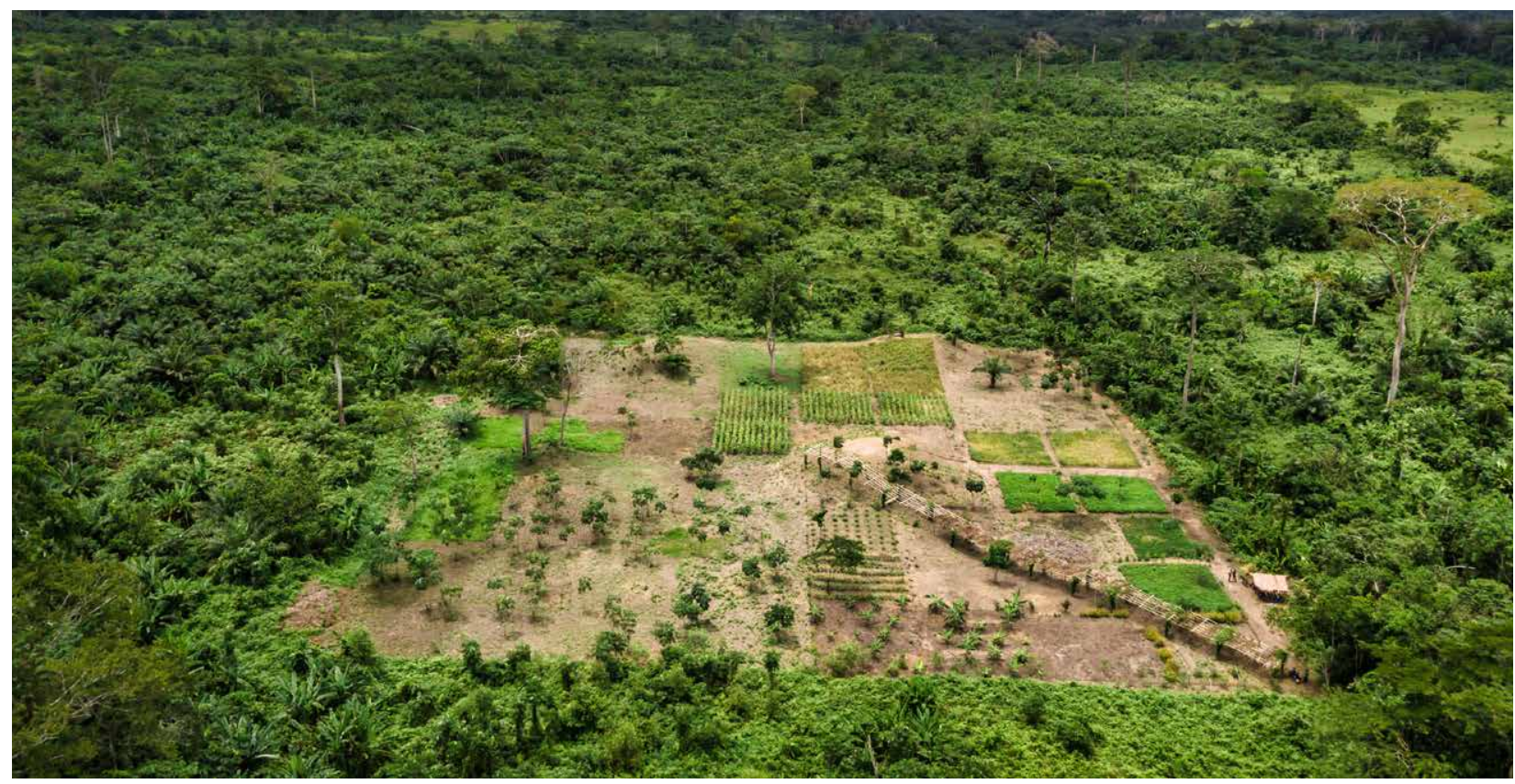

Mô hình nông trại Yangambi - Cộng hoà Congo. Ảnh chụp bởi Axel Fassio/CIFOR

ràng là khi các bên được bảo hộ bởi cả chính sách tiếp cận thông tin của mỗi quốc gia. Bên cạnh đó, những thông tin được công bố thực sự đáng tin cậy trong việc cung cấp bức tranh toàn cảnh về về hiệu quả hoạt động của các cơ quan chính phủ và thể chế, chỉ rõ trách nhiệm của các quan chức cũng như nguồn quỹ công được sử dụng cho mục đích nào, đồng thời tạo ra quy trình tham gia và kiểm tra chéo để các bên có thể đóng góp ý kiến trong quá trình xây dựng chiến lược. Fox (2007) cho rằng trên thế giới hiện nay có 2 loại hình minh bạch trong quá trình ra quyết định:

a. minh bạch thực chất. Nếu mục đích của minh bạch là nhằm đảm bảo sự vận hành của hệ thống thì các thông tin cần phải chỉ rõ ai làm việc gì ? ai chịu trách nhiệm gì ? ai có quyền gì ? và ai hướng lợi và nhận được gì ?

b. minh bạch hình thức. Đó là khi thông tin được công bố không đầy đủ, hoặc chỉ trên danh nghĩa, hoặc không đáng tin cậy.

Quá trình minh bạch hóa cũng có nhiều phương thức: tự nguyện, bắt buộc trên danh nghĩa và thực sự bắt buộc. Tuy nhiên, việc giám sát và thực thi pháp luật là mấu chốt quan trọng để có thể thực hiện được mục tiêu của quá trình minh bạch hóa.

\section{Định nghĩa và phương thức tiếp cận trong việc đánh giá trách nhiệm giải trình}

Trách nhiệm giải trình là một bộ tiêu chuẩn để đánh giá hành vi của các chủ thể công. Trách nhiệm giải trình hay chính xác hơn là chịu trách nhiệm được coi là một phẩm chất tích cực của các tổ chức hoặc viên chức. Do đó, các nghiên cứu về trách nhiệm giải trình thường tập trung vào các vấn đề quy phạm, về việc đánh giá hành vi thực tế và hoạt động của các cơ quan công quyền (Bovens 2014). Hay nói một cách khác, trách nhiệm giải trình thuộc cả về tổ chức, thể chế và cả về cá nhân. Fox (2007) cho rằng có hai khía cạnh cần xem xét của trách nhiệm giải trình:

- Năng lực và quyền yêu cầu câu trả lời

- Khả năng xử phạt nếu không thực hiện trách nhiệm giải trình.

Mặc dù có nhiều khung đánh giá trách nhiệm giải trình, khung đánh giá do Mashaw (2006) đề ra với 6 câu hỏi chính là khung phương pháp được sử dụng rộng rãi. 6 câu hỏi trong khung đánh giá của Mashaw (2006) bao gồm:

1. Ai là người phải chịu trách nhiệm giải trình?

2. Trách nhiệm giải trình phải báo cáo với ai?

3. Trách nhiệm giải trình về vấn đề gì? 
4. Quá trình chứng minh trách nhiệm giải trình diễn ra như thế nào?

5. Cơ quan và tổ chức dùng chuẩn mực nào để đánh giá trách nhiệm giải trình?

6. Điều gì sẽ xảy ra khi các cơ quan đơn vị không thực hiện được các chuẩn mực này?

\section{Các yếu tố ảnh hưởng tới hiệu quả và tác động của việc thực thi tính minh bạch và trách nhiệm giải trình}

Các bên có liên quan thường tin rằng nếu thực hiện minh bạch hóa và trách nhiệm giải trình tốt thì có thể cải thiện được quản trị lâm nghiệp. Tuy nhiên, trong thực tế tác động của tính minh bạch trong việc cải thiện và nâng cao chất lượng quản trị lâm nghiệp phụ thuộc vào rất nhiều yếu tố như lĩnh vực chính sách ngành nghề công, thể chế chính trị và đặc điểm dân số (de Fine Licht 2014; de Fine Licht và cộng sự 2014; Grimmelikhuijsen và Meijer 2014; Porumbescu 2015).

Ba câu hỏi chính (i) minh bạch có thể làm gì; (ii) minh bạch không thể làm gì và (iii) trong điều kiện nào thì minh bạch phát huy tác động lớn nhất luôn được đặt ra bởi các nhà hoạch định chính sách, bởi trên thực tế, minh bạch có thể rất phù hợp để giải quyết một số vấn đề nhất định nhưng lại không phù hợp để giải quyết những vấn đề khác (Cucciniello và cộng sự 2017). Fox (2007) qua nhiều nghiên cứu đã chỉ ra rằng có rất ít các bằng chứng thuyết phục cho việc cung cấp thông tin tốt hơn và nhiều hơn được đã cải thiện được tính minh bạch và tính giải trình của hệ thống chính trị. Trong thực tế, tính minh bạch và trách nhiệm giải trình được hiểu khác nhau và cách mọi người xác định tính minh bạch và trách nhiệm giải trình phụ thuộc vào mục tiêu chính trị, mối quan hệ quyền lực giữa các bên, thế chế và văn hóa của quốc gia hay tổ chức, trình độ nhận thức và mối quan tâm chính trị của công chúng. Trong rất nhiều trường hợp, cải cách tiến tới minh bạch hóa không phải lúc nào cũng có hiệu ứng tích cực, bởi nhiều khi nó đã dẫn đến tình trạng lạm dụng quyền lực để thâu tóm thông tin hay giúp các bên phạm tội có điều kiện tiếp cận thông tin dễ dàng hơn để trục lợi (Fox 2007).

\section{Nâng cao tính minh bạch và trách nhiệm giải trình trong việc thực hiện chính sách lâm nghiệp tại Việt Nam}

Trong những năm gần đây, Nhà nước đã chú trọng hơn về vấn đề minh bạch và trách nhiệm giải trình, cụ thể qua những điều Luật Phòng, chống tham nhũng 2018 36/2018/QH14 (Quốc hội 2018) (Xin xem thêm Hộp 1) và Luật tiếp cận thông tin 2016 104/2016/QH13 (Quốc hội 2016) (Xin xem thêm Hộp 2).

Hộp 1. Luật Phòng, chống tham nhũng 2018 36/2018/QH14 (Quốc hội 2018)

Luật Phòng, chống tham nhũng quy định các cơ quan, tổ chức, đơn vị phải công khai, minh bạch theo quy định của pháp luật về các nội dung sau đây:

- Việc thực hiện chính sách, pháp luật có nội dung liên quan đến quyền, lợi ích hợp pháp của cán bộ, công chức, viên chức; người lao động; cán bộ, chiến sĩ trong lực lượng vũ trang và công dân;

- Việc bố trí, quản lý, sử dụng tài chính công, tài sản công hoặc kinh phí huy động từ các nguồn hợp pháp khác;

- Công tác tổ chức cán bộ của cơ quan, tổ chức, đơn vị; quy tắc ứng xử của người có chức vụ, quyền hạn;

- Việc thực hiện chính sách, pháp luật có nội dung không thuộc trường hợp quy định tại các điểm a, b và c khoản này mà theo quy định của pháp luật phải công khai, minh bạch.

Cơ quan, tổ chức, đơn vị trực tiếp giải quyết công việc của cơ quan, tổ chức, đơn vị, cá nhân khác ngoài nội dung công khai, minh bạch quy định tại khoản 1 Điều này còn phải công khai, minh bạch về thủ tục hành chính (Điều 10).

Hình thức công khai bao gồm: a) tại cuộc họp của cơ quan, tổ chức, đơn vị; b) Niêm yết tại trụ sở của cơ quan, tổ chức, đơn vị; c) Thông báo bằng văn bản đến cơ quan, tổ chức, đơn vị, cá nhân có liên quan; d) Phát hành ấn phẩm; đ) Thông báo trên phương tiện thông tin đại chúng; e) Đăng tải trên cổng thông tin điện tử, trang thông tin điện tử; g) Tổ chức họp báo; h) Cung cấp thông tin theo yêu cầu của cơ quan, tổ chức, đơn vị, cá nhân (Điều 11). 


\section{Hộp 2. Luật tiếp cận thông tin 2016}

Luật tiếp cận thông tin 2016 chỉ rõ quyền và nghĩa vụ công dân trong việc tiếp cận thông tin; đơn vị giám sát đảm bảo quyền; nội dung, hình thức và thời điểm công khai thông tin. Trong đó, công dân có quyền a) Được cung cấp thông tin đầy đủ, chính xác, kịp thời; b) Khiếu nại, khởi kiện, tố cáo hành vi vi phạm pháp luật về tiếp cận thông tin. Đồng thời, công dân có nghĩa vụ a) Tuân thủ quy định của pháp luật về tiếp cận thông tin; b) Không làm sai lệch nội dung thông tin đã được cung cấp; c) Không xâm phạm quyền và lợi ích hợp pháp của cơ quan, tổ chức hoặc của người khác khi thực hiện quyền tiếp cận thông tin (Điều 8). Về mặt giám sát, Quốc hội giám sát tối cao việc bảo đảm thực hiện quyền tiếp cận thông tin của công dân; Hội đồng nhân dân giám sát việc bảo đảm thực hiện quyền này ở cấp địa phương và xem xét báo cáo hằng năm; và Mặt trận Tổ quốc Việt Nam và các tổ chức thành viên có trách nhiệm giám sát xã hội việc bảo đảm thực hiện quyền này (Điều 10).

Luật cũng quy định cụ thể các thông tin sau đây phải được công khai rộng rãi:

a. Văn bản quy phạm pháp luật; văn bản hành chính có giá trị áp dụng chung; điều ước quốc tế mà nước Cộng hòa xã hội chủ nghĩa Việt Nam là thành viên, thỏa thuận quốc tế mà Việt Nam là một bên; thủ tục hành chính, quy trình giải quyết công việc của cơ quan nhà nước;

b. Thông tin phổ biến, hướng dẫn thực hiện pháp luật, chế độ, chính sách đối với những lĩnh vực thuộc phạm vi quản lý của cơ quan nhà nước;

c. Dự thảo văn bản quy phạm pháp luật theo quy định của pháp luật về ban hành văn bản quy phạm pháp luật; nội dung và kết quả trưng cầu ý dân, tiếp thu ý kiến của Nhân dân đối với những vấn đề thuộc thẩm quyền quyết định của cơ quan nhà nước mà đưa ra lấy ý kiến Nhân dân theo quy định của pháp luật; đề án và dự thảo đề án thành lập, giải thể, nhập, chia đơn vị hành chính, điều chỉnh địa giới hành chính;

d. Chiến lược, chương trình, dự án, đề án, kế hoạch, quy hoạch phát triển kinh tế - xã hội của quốc gia, địa phương; quy hoạch ngành, lĩnh vực và phương thức, kết quả thực hiện; chương trình, kế hoạch công tác hằng năm của cơ quan nhà nước;

e. Thông tin về dự toán ngân sách nhà nước; báo cáo tình hình thực hiện ngân sách nhà nước; quyết toán ngân sách nhà nước; dự toán, tình hình thực hiện, quyết toán ngân sách đối với các chương trình, dự án đầu tư xây dựng cơ bản sử dụng vốn ngân sách nhà nước; thủ tục ngân sách nhà nước;

f. Thông tin về phân bổ, quản lý, sử dụng nguôn vốn hỗ trợ phát triển chính thức và nguồn viện trợ phi chính phủ theo quy định; thông tin về quản lý, sử dụng các khoản cứu trợ, trợ cấp xã hội; quản lý, sử dụng các khoản đóng góp của Nhân dân, các loại quỹ;

g. Thông tin về danh mục dự án, chương trình đầu tư công, mua sắm công và quản lý, sử dụng vốn đầu tư công, tình hình và kết quả thực hiện kế hoạch, chương trình, dự án đầu tư công; thông tin về đấu thầu; thông tin về quy hoạch, kế hoạch sử dụng đất; giá đất; thu hồi đất; phương án bồi thường, giải phóng mặt bằng, tái định cư liên quan đến dự án, công trình trên địa bàn;

h. Thông tin về hoạt động đầu tư, quản lý, sử dụng vốn nhà nước tại doanh nghiệp; báo cáo đánh giá kết quả hoạt động và xếp loại doanh nghiệp; báo cáo giám sát tình hình thực hiện công khai thông tin tài chính của doanh nghiệp và cơ quan nhà nước đại diện chủ sở hữu; thông tin về tổ chức và hoạt động của doanh nghiệp nhà nước;

i. Thông tin về sản phẩm, hàng hóa, dịch vụ có tác động tiêu cực đến sức khỏe, môi trường; kết luận kiểm tra, thanh tra, giám sát liên quan đến việc bảo vệ môi trường, sức khỏe của cộng đồng, an toàn thực phẩm, an toàn lao động;

j. Thông tin về chức năng, nhiệm vụ, quyền hạn, cơ cấu tổ chức của cơ quan và của đơn vị trực thuộc; nhiệm vụ, quyền hạn của cán bộ, công chức trực tiếp giải quyết các công việc của Nhân dân; nội quy, quy chế do cơ quan nhà nước ban hành;

k. Báo cáo công tác định kỳ; báo cáo tài chính năm; thông tin thống kê về ngành, lĩnh vực quản lý; cơ sở dữ liệu quốc gia ngành, lĩnh vực; thông tin về tuyển dụng, sử dụng, quản lý cán bộ, công chức, viên chức; thông tin về danh mục và kết quả chương trình, đề tài khoa học;

I. Danh mục thông tin phải công khai theo quy định tại điểm b khoản 1 Điều 34 của Luật này; tên, địa chỉ, số điện thoại, số fax, địa chỉ thư điện tử của cơ quan nhà nước hoặc người làm đầu mối tiếp nhận yêu cầu cung cấp thông tin; 
Hộp 2. Tiếp trang trước

m. Thông tin liên quan đến lợi ích công cộng, sức khỏe của cộng đồng;

n. Thông tin về thuế, phí, lệ phí;

o. Thông tin khác phải được công khai theo quy định của pháp luật.

Ngoài thông tin quy định tại khoản 1 Điều này, căn cứ vào điều kiện thực tế, cơ quan nhà nước chủ động công khai thông tin khác do mình tạo ra hoặc nắm giữ (Điều 17) dưới nhiều hình thức:

a. Đăng tải trên cổng thông tin điện tử, trang thông tin điện tử của cơ quan nhà nước;

b. Công khai trên phương tiện thông tin đại chúng;

c. Đăng Công báo;

d. Niêm yết tại trụ sở cơ quan nhà nước và các địa điểm khác;

e. Thông qua việc tiếp công dân, họp báo, thông cáo báo chí, hoạt động của người phát ngôn của cơ quan nhà nước theo quy định của pháp luật;

f. Các hình thức khác thuận lợi cho công dân do cơ quan có trách nhiệm công khai thông tin xác định.

Thời điểm công khai thông tin đối với từng lĩnh vực được thực hiện theo quy định của pháp luật có liên quan; trường hợp pháp luật chưa có quy định thì chậm nhất là 05 ngày làm việc kể từ ngày tạo ra thông tin, cơ quan nhà nước có thẩm quyền phải công khai thông tin (Điều 18).

Tuy nhiên, người dân không có quyền tiếp cận thông tin mật và có tính nhạy cảm. Cụ thể: 1. Thông tin thuộc bí mật nhà nước, bao gồm những thông tin có nội dung quan trọng thuộc lĩnh vực chính trị, quốc phòng, an ninh quốc gia, đối ngoại, kinh tế, khoa học, công nghệ và các lĩnh vực khác theo quy định của luật. Người dân chỉ được tiếp cận này nếu thông tin này đã được giải mật. 2 . Thông tin mà nếu để tiếp cận sẽ gây nguy hại đến lợi ích của Nhà nước, ảnh hưởng xấu đến quốc phòng, an ninh quốc gia, quan hệ quốc tế, trật tự, an toàn xã hội, đạo đức xã hội, sức khỏe của cộng đồng; gây nguy hại đến tính mạng, cuộc sống hoặc tài sản của người khác; thông tin thuộc bí mật công tác; thông tin về cuộc họp nội bộ của cơ quan nhà nước; tài liệu do cơ quan nhà nước soạn thảo cho công việc nội bộ (Điều 6). Tuy nhiên, định nghĩa cụ thể về bí mật nhà nước và thông tin gây hại chưa được nêu rõ.

Mặc dù khung pháp lí và chính sách của Việt Nam đã đề cao mục tiêu minh bạch thông tin và nâng cao trách nhiệm giải trình, việc thực hiện các cam kết này của Việt Nam trong lĩnh vực lâm nghiệp còn gặp nhiều thách thức, cụ thể hơn:

\section{Sự sẵn có, độ tin cậy và sự chính xác về số liệu còn} hạn chế. Do kinh phí hạn hẹp, nhiều số liệu liên quan đến diện tích và chất lượng rừng còn chưa có hoặc chưa được cập nhật. Để đánh giá tác động của các chính sách đối với đời sống của người dân và cải thiện chất lượng dịch vụ môi trường rừng cần sự theo dõi và kinh phí dài hơi nhưng chưa được chú trọng và quan tâm. Ngoài ra, việc chưa có một phương pháp thu thập số liệu thống nhất giữa các ngành các Bộ ngành cũng dẫn đến việc khó khăn trong việc phân tích và xử lí số liệu. Kiểm kê khí nhà kính quốc gia cũng gặp nhiều khó khăn do thiếu số liệu đủ độ tin cậy. GreenID (2014) nhận thấy việc kiểm kê thường thiếu độ chi tiết, thiếu chính xác và thiếu các chuyên gia trong lĩnh vực kiểm kê khí nhà kính ở cấp Bộ và ngành.

\section{Quy trình tham gia của người dân vào quá trình ra} chính sách đã được đề cao trong nhiều văn bản và chính sách, nhưng tại cấp cơ sở, người dân còn gặp nhiều khó khăn trong việc tiếp cận các thông tin và tham gia vào quá trình thiết kế, thực thi và giám sát chính sách liên quan đến bảo vệ và phát triển rừng. Dù vậy, Phạm và các cộng sự (2014) cũng đã chỉ ra nỗ lực của Việt Nam trong việc tạo ra diễn đàn và hành lang pháp lí cho các tổ chức phi chính phủ, các tổ chức nước ngoài tham gia đóng góp ý kiến trong quá trình xây dựng chính sách ở phường, thị trấn. Cũng đã có xác định yêu cầu về sự tham gia hiệu quả, bao gồm thông tin người dân cần phải được cung cấp, những gì họ được thảo luận, biểu quyết và quyết định, về cách thức đưa ra các ý kiến trước khi quyết định được cơ quan có thẩm quyền ban hành. 


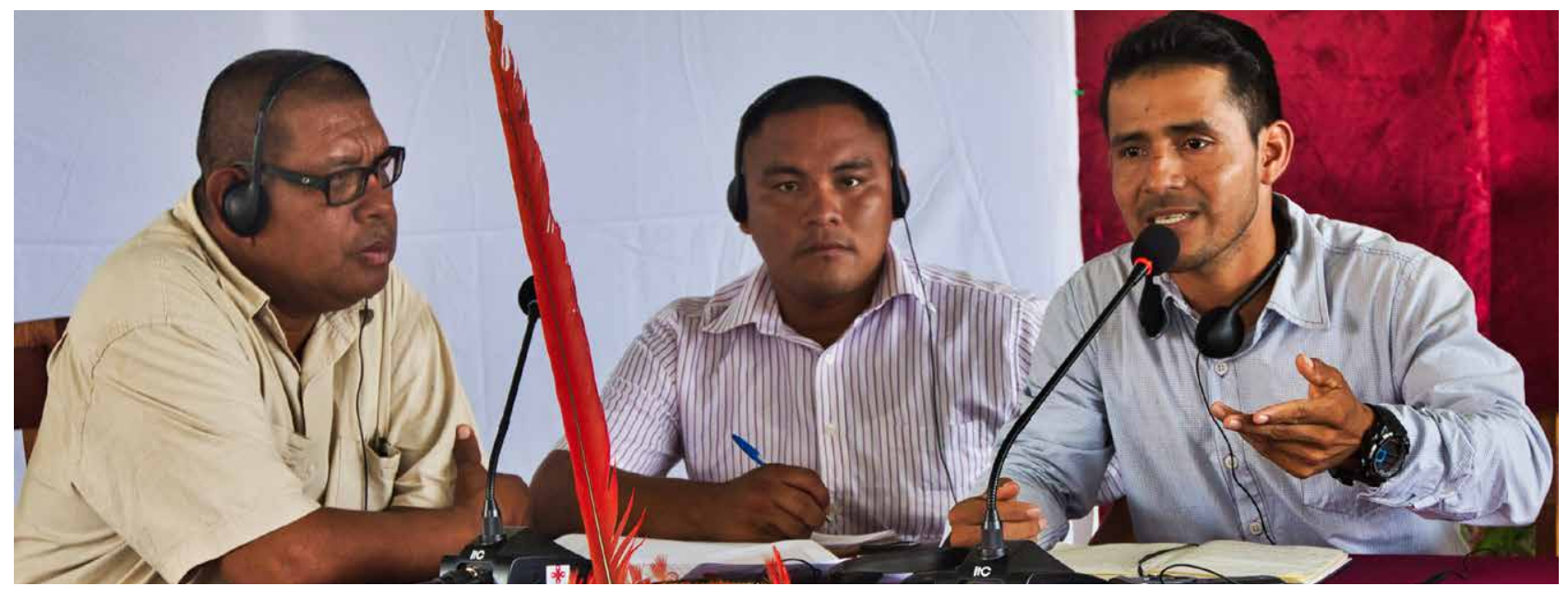

Đại biểu thảo luận về kinh nghiệm cộng đồng của họ trong hội thảo về săn bắn bên vưng ở Aishalton, Guyana. Ảnh chụp bởi Barbara Fraser/CIFOR

Tuy nhiên, các thông tin được truyền tải đến người dân thường kém hiệu quả, một phần vì chưa được thực hiện trên ngôn ngữ bản địa, và sử dụng các kênh thông tin mà người dân ít biết đến hoặc không thể tiếp cận được.

Chia sẻ thông tin giữa các bên còn hạn chế. Như đã trình bày ở phần trên, một hệ thống minh bạch và có tính giải trình cao cần phải được thể hiện và đảm bảo qua việc Nhà nước và các tổ chức chủ động công khai cùng với trách nhiệm cung cấp các thông tin theo nhu cầu và yêu cầu các bên. Đối với bối cảnh của ngành lâm nghiệp, các cơ quan nhà nước đã chủ động công khai chia sẻ các dữ liệu liên quan đến diện tích và chất lượng rừng hàng năm; tình hình bảo vệ và phát triển rừng ở các địa phương đều được chia sẻ rộng rãi qua nhiều kênh thông tin. Tuy nhiên, việc chia sẻ các thông tin theo yêu cầu của các bên còn hạn chế. Mặc dù các luật định đều yêu cầu các bên phải chia sẻ thông tin theo một thời hạn nhất định, trên thực tế, việc thực thi pháp luật, giám sát và đánh giá việc chia sẻ thông tin theo luật định chưa được tiến hành thường xuyên và kịp thời. Chưa có chế tài xử phạt rõ ràng khi các bên không thực hiện chia sẻ thông tin theo quy định. Ngoài ra, đảm bảo tính minh bạch và trách nhiệm giải trình liên quan đến chính sách lâm nghiệp của Việt Nam đòi hỏi có sự điều phối giữa các bộ và các ngành, nhưng quan trọng hơn nữa, cần có các cam kết chính trị trong việc biên soạn và công bố thông tin và số liệu đúng thời hạn va đầy đủ.
Thực hiện đồng thời cả 3 khía cạnh của minh bạch. Như đã trình bày ở trên, khi đề cập tới minh bạch, cần xem xét cả minh bạch về thể chế chính trị, minh bạch về hành chính và minh bạch về ngân sách, tài chính. Trong ngành lâm nghiệp, phần lớn các đánh giá chỉ tập trung vào minh bạch trong sử dụng tài chính và ngân sách. Cùng tiến hành đánh giá, cải thiện và nâng cao tính minh bạch trong thể chế và hành chính sẽ nâng cao tính minh bạch và trách nhiệm giải trình trong thực thi chính sách ngành lâm nghiệp.

Việc thực thi, theo dõi, giám sát và đánh giá việc thực thi các chính sách liên quan đến minh bạch và trách nhiệm giải trình đòi hỏi định nghĩa, phương pháp đánh giá rõ ràng, nâng cao năng lực cho các bên có liên quan trong lĩnh vực chia sẻ thông tin, đồng thời cải thiện hành lang pháp lí liên quan đến thực thi chính sách kịp thời và đầy đủ.

\section{Lời cảm ơn}

Nghiên cứu này là một phần trong nghiên cứu so sánh toàn cầu về REDD + của CIFOR (www.cifor.org/gcs). Chúng tôi xin chân thành cảm ơn các nhà tài trợ đã hỗ trợ nghiên cứu này bao gồm Cơ quan Hợp tác Phát triển $\mathrm{Na} U y$ (NORAD), Liên minh Châu Âu (EU), Sáng kiến Khí hậu Quốc tế (IKI) của Bộ Môi trường, Bảo tồn Thiên nhiên, Xây dựng và $A n$ toàn Hạt nhân của Đức (BMUB) và Chương trình nghiên cứu CGIAR về rừng, cây và nông lâm kết hợp (CRPFTA) được hỗ trợ tài chính từ các nhà tài trợ quỹ CGIAR. 


\section{Tài liệu tham khảo}

Ball, C. (2009). What is transparency?. Public Integrity, 11(4), 293-308.

Bovens, M. (2010). Two Concepts of Accountability: Accountability as a Virtue and as a Mechanism. West European Politics, 33(5), 946-967.

Brockhaus, M., Di Gregorio, M., \& Mardiah, S. (2014). Governing the design of national REDD+: An analysis of the power of agency. Forest Policy and Economics, 49, 23-33.

Cucciniello, M., \& Nasi, G. (2014). Transparency for trust in government: How effective is formal transparency?. International Journal of Public Administration, 37(13), 911-921.

Cucciniello, M., Porumbescu, G. A., \& Grimmelikhuijsen, S. (2017). 25 years of transparency research: Evidence and future directions. Public Administration Review, 77(1), 32-44. de Fine Licht, J. (2014). Policy area as a potential moderator of transparency effects: An experiment. Public Administration Review, 74(3), 361-371.

De Fine Licht, J., Naurin, D., Esaiasson, P., \& Gilljam, M. (2014). When does transparency generate legitimacy? Experimenting on a context-bound relationship. Governance, 27(1), 111-134.

[GreenID] Green Innovation and Development Centre. 2014. Assessment of policies on GHG mitigation in Vietnam. Hanoi: Green ID.

Environmental Democracy Index. (2015). Environmental Democracy Index. World Resource Institute. https:// environmentaldemocracyindex.org/.

Estrada, M. (2011). Standards and methods available for estimating project-level REDD+ carbon benefits: reference guide for project developers. CIFOR Working Paper, (52).

Fox, J. (2007). The uncertain relationship between transparency and accountability. Development in practice, 17(4-5), 663-671.

Grimmelikhuijsen, S. G., \& Meijer, A. J. (2014). Effects of transparency on the perceived trustworthiness of a government organization: Evidence from an online experiment. Journal of Public Administration Research and Theory, 24(1), 137-157.

Heald, D. (2012). Why is transparency about public expenditure so elusive?. International review of administrative sciences, 78(1), 30-49.

Korhonen-Kurki, K., Brockhaus, M., Bushley, B., Babon, A., Gebara, M. F., Kengoum, F., ... \& Maharani, C. (2015). Coordination and cross-sectoral integration in REDD+: experiences from seven countries. Climate and Development, 8(5), 458-471.

Mashaw, J. (2016). Public Reason and Administrative Legitimacy'in John Bell and others. Public law adjudication in common law systems: process and substance.

Meijer, A., 't Hart, P., \& Worthy, B. (2018). Assessing government transparency: an interpretive framework. Administration \& Society, 50(4), 501-526.

Piotrowski, S. J., \& Van Ryzin, G. G. (2007). Citizen attitudes toward transparency in local government. The American Review of Public Administration, 37(3), 306-323.

Porumbescu, G. A. (2015). Using transparency to enhance responsiveness and trust in local government: can it work?. State and Local Government Review, 47(3), 205-213.

Quốc hội Việt Nam. (2016). Luật tiếp cận thông tin 2016 (104/2016/QH13). Quốc hội: Hà Nội, Việt Nam. https:// thuvienphapluat.vn/van-ban/Bo-may-hanh-chinh/Luattiep-can-thong-tin-2016-280116.aspx\#tab-1

Quốc hội Việt Nam. (2018). Luật Phòng, chống tham nhũng 2018. 36/2018/QH14. Quốc hội: Hà Nội, Việt Nam. https:// thuvienphapluat.vn/van-ban/bo-may-hanh-chinh/LuatPhong-chong-tham-nhung-322049.aspx.

Ravikumar, A., Larson, A., Duchelle, A., Myers, R., \& Tovar, J. G. (2015). Multilevel governance challenges in transitioning towards a national approach for REDD+: evidence from 23 subnational REDD+ initiatives. International Journal of the Commons, 9(2). Schnell, S. (2018). From information to predictability: Transparency on the path to democratic governance. The case of Romania. International Review of Administrative Sciences, 84(4), 692-710.

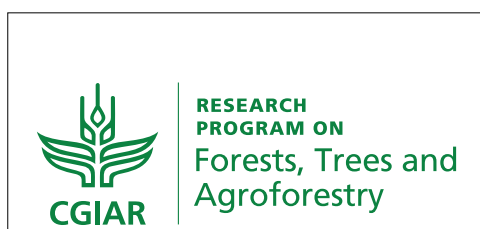

Chương trình nghiên cứu của CGIAR về Rừng, Cây gỗ và Nông lâm kết hợp (FTA) là chương trình phát triển nghiên cứu lớn nhất thế giới nhằm nâng cao vai trò của rừng, cây gỗ và nông lâm kết hợp với mục tiêu phát triển bền vững và đảm bảo lương thực để ứng phó với biến đổi khí hậu. CIFOR chủ trì các nghiên cứu FTA trong mối quan hệ đối tác chiến lược với Bioversity International, CATIE, CIRAD, INBAR, ICRAF và TBI.

Nghiên cứu này được hỗ trợ bởi Quỹ đối tác CGIAR: cigar.org/funders/

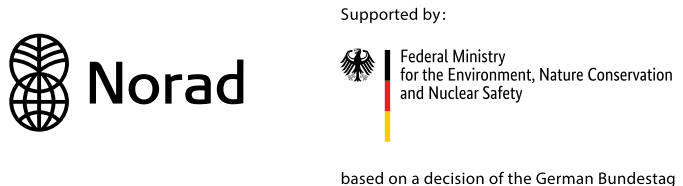
nghiên cứu sáng tạo, nâng cao năng lực của các bên đối tác, tích cực tham gia đối thoại với các bên liên quan để hỗ trợ định hình chính sách và thực tiễn tác động tới rừng và con người. CIFOR là tổ chức nghiên cứu thuộc liên minh CGIAR và chủ trì các chương trình nghiên cứu của CGIAR về Rừng, Cây gỗ và Nông lâm kết hợp (FTA). Trụ sở chính của CIFOR đặt tại Bogor, Indonesia và các văn phòng của CIFOR có mặt tại Nairobi, Kenya; Yaounde, Cameroon; Lima, Peru và Bonn, Germany. 